Revista de Negócios_ISSN 1980.4431_vol. 19, n. 4, p. 21_42 2014_DOI:10.7867/1980-

4431.2014v19n4p21_42

\title{
Setor de gemas e joias da região metropolitana de Belo Horizonte: Um estudo preliminar sob a perspectiva da aglomeração de empresas
}

\section{Gems and jewelry industry in Belo Horizonte area: A preliminary study under the cluster of firms perspective}

\author{
Paula Karina Salume \\ Pontifícia Universidade Católica de Minas Gerais - Brasil \\ paulasalume@hotmail.com \\ Liliane Oliveira Guimarães \\ Pontifícia Universidade Católica de Minas Gerais - Brasil \\ lilianeog@pucminas.br \\ Denise de Castro Pereira \\ Pontifícia Universidade Católica de Minas Gerais - Brasil \\ dpereira@pucminas.br \\ José Márcio de Castro \\ Pontifícia Universidade Católica de Minas Gerais - Brasil \\ josemarcio@pucminas.br
}

Recebido em 11 de junho de 2014. Alterado em 11 de outubro de 2014. Aprovado em 24 de outubro de 2014. Editores Responsáveis: Edson Roberto Scharf, Dr. e Marianne Hoeltgebaum, Dr.

Processo de avaliação por double blind review

\section{Resumo}

A produção mineral tem importância econômica muito grande para o Estado de Minas Gerais. O presente artigo teve como objetivo analisar o segmento de gemas e joias da Região Metropolitana de Belo Horizonte (RMBH) sob a perspectiva da aglomeração de empresas, avaliando se este apresenta características que possam identificá-lo como arranjo produtivo local. Para tal, foi adotado o modelo proposto por Lübeck, Wittman e Silva (2012), do qual foram extraídas e analisadas as variáveis: Capital Social, Rede de empresas, Inovação, Políticas públicas e realizado o cálculo do quociente locacional. Um roteiro de entrevistas foi elaborado com base nessas variáveis. Devido à característica exploratória e inicial deste estudo, optou-se por entrevistar sete atores que participam direta ou indiretamente do segmento de gemas e joias da Região Metropolitana de Belo Horizonte. Na fase de análise dos dados, julgou-se pertinente a utilização da análise de conteúdo, elaborada seguindo-se as recomendações de Bardin (1977), que sugere a categorização dos depoimentos conforme variáveis definidas pelo modelo teórico de referência no trabalho. Em linhas gerais, foi constatado que o segmento de gemas e joias da 
Setor de gemas e joias da região metropolitana de Belo Horizonte: Um estudo preliminar sob a perspectiva da aglomeração de empresas

RMBH não apresenta as condições apontadas pelos autores como necessárias para a caracterização de um APL. Tomando como referência algumas das variáveis do modelo de Lübeck, Wittman e Silva (2012), a aglomeração analisada apresenta baixo capital social e inovação incipiente, rede de empresas pouco significativa e ausência de políticas públicas destinadas ao setor. Adicionalmente, o resultado pouco superior a um do quociente locacional da Região Metropolitana de Belo Horizonte não permite afirmar a existência da especialização produtiva no segmento. Posteriormente à análise de cada variável do modelo, foram elaboradas proposições para serem testadas em estudos futuros. Acredita-se que dada a importância histórica e econômica do setor para o Estado, os resultados podem contribuir para subsidiar políticas públicas no sentido de desenvolver ações que fortaleçam o segmento, bem como projetos de associações de classe de forma a tornar mais competitiva a aglomeração da RMBH e, consequentemente, ajudar a promover o desenvolvimento econômico local e regional.

Palavras-chave: Aglomerações de empresas. Setor de gemas e joias. Capital social. Rede de empresas. Políticas públicas. Inovação. Quociente locacional.

\footnotetext{
Abstract

Given the importance of mineral production for Minas Gerais State, Brazil, this article aims to analyze the segment of gems and jewelry of Belo Horizonte and surroundings in light of firm clusters. More specifically, we aim to identify whether this segment presents characteristics that can be framed in terms of cluster approach. In doing so, we follow Lubeck, Wittman and Silva's model (2012) by selecting the following categories: social capital, firm networks, innovation, public policy and quoted location. An interview schedule was sketched accordingly. Because our study is exploratory we interviewed seven actors that either directly or indirectly participated in such cluster. In terms of data analysis, we used content analysis based on Bardin (1977) who suggest categorizing the interviews in accordance with the categories defined in the theoretical model. Broadly, we found that the segment gems and jewelry does not present the characteristics needed to classify it into cluster. With reference to the categories researched here, this cluster presents relatively low social capital and incipient innovation. Its firm network is significantly low and there is no specific public policy. In addition, the fact that that result is slightly superior of 1 of location quocient does not allow us to point out to the existence of productive specialization of the seg-
}

ment. After data analysis, we put forward propositions for future test. In addition, we believe the results can contribute to subsidize the formulation of public policies for developing actions that strengthen the segment as well as local organizations' projects that foster this segment competitiveness and as a result, help promoting local and regional socio-economic development.

Keywords: Clusters. Segment of gems and jewelry. Social capital. Firm network. Public policy. Innovation. Location quocient.

\section{Introdução}

A formação do Estado de Minas Gerais está estreitamente relacionada com o processo de descobrimento e exploração mineral ocorrida principalmente nos séculos XVII e XVIII. Minas Gerais representou a principal região da federação de produção do ouro, "produto que determinou um ciclo da economia brasileira e cuja exploração está relacionada à urbanização e ao patrimônio artístico produzidos no século XVII" (BOTELHO, 2009, p. 54). Além do ouro, o Estado é pródigo em produzir diamantes, particularmente ao norte da capital, na cidade de Diamantina, e pedras preciosas coradas nos Vales do Mucuri, Jequitinhonha e Rio Doce, no nordeste do Estado de Minas Gerais. Essas regiões representam uma das maiores províncias gemológicas do mundo (HENRIQUES; SOARES, 2005).

Em virtude dessa tradição mineral do Estado, parecem ter sido naturais e decorrentes a constituição e a multiplicação de empresas especializadas na produção de joias na Região Metropolitana de Belo Horizonte (RMBH). Nas cidades que compõem a RMBH estão $80 \%$ das empresas do setor joalheiro do Estado (Instituto Brasileiro de Gemas e Metais Preciosos [IBGM], 2010).

Como forma de aumentar a competitividade do setor, o sistema Sindijoias/Ajomig (Sindicato das 
Indústrias de Joalheria, Ourivesaria, Lapidação de Pedras Preciosas e Relojoaria de Minas Gerais e Associação dos Joalheiros, Empresários de Pedras Preciosas, Relógios e Bijuterias de Minas Gerais) tem envidado esforços no sentido de constituir e organizar o arranjo joalheiro na região. Dentre as iniciativas, desde 2004, analisa-se a possibilidade de criação do Polo Industrial de Gemas, Diamantes e Joias no Aeroporto Industrial de Confins, com o objetivo de, além de aumentar a competitividade interna e externa das empresas e do setor, incrementar exportações de joias, promover a formalização das empresas da cadeia produtiva, dentre outros (IBGM, 2010).

Sabe-se, no entanto, que a formação e o desenvolvimento de um arranjo não é fruto apenas de interesse de classe ou político, mas decorrência de uma conjunção de fatores relacionados, por exemplo, à capacidade de cooperação interfirmas, à utilização do capital social disponível e à possibilidade de gerar inovação no setor (LÜBECK; WITTMAN; SILVA, 2012).

É nesse sentido que se insere a questão que norteou a elaboração deste trabalho. Considerando-se os pressupostos que definem e caracterizam um arranjo produtivo local, o setor de gemas e joias da Região Metropolitana de Belo Horizonte pode ser classificado como arranjo?

Nesse sentido, o objetivo neste trabalho foi analisar o segmento de gemas e joias da Região Metropolitana de Belo Horizonte (RMBH) sob a perspectiva da aglomeração de empresas, avaliando se este apresenta características que possam identificá-lo como arranjo produtivo local.

Para o desenvolvimento da pesquisa foi utilizado um estudo de caso de natureza qualitativa, com a realização de sete entrevistas com pessoas que atuam no setor, inclusive com o presidente do Sindijoias. A análise dos dados tomou como referências as variáveis estabelecidas por Lübeck, Wittman e Silva (2012) - capital social, redes de empresa, inovação, políticas públicas e cálculo do quociente locacional. A análise dessas variáveis a partir da categorização dos depoimentos e dados documentais permitiu inferir que o segmento de gemas e joias da RMBH não apresenta as condições apontadas pelos autores como necessárias para a caracterização de um APL.

Este artigo foi estruturado conforme se apresenta a seguir. A partir desta introdução, discutiu-se o referencial teórico que subsidiou a análise dos dados coletados, com ênfase na apresentação das variáveis do modelo de Lübeck, Wittman e Silva (2012) para identificação de um APL. No item três, apresentaram-se os procedimentos metodológicos utilizados para o desenvolvimento da pesquisa. A análise dos dados e resultados foram discutidos no item quatro e, por fim, no item cinco, as considerações finais com sugestões para estudos futuros.

\section{Referencial teórico}

Seguem os levantamentos bibliográficos que referenciam o trabalho.

\subsection{Aglomeração de empresas e os ar- ranjos produtivos locais (APLs)}

A importância da concentração de empresas em determinadas localidades já era destacada pelos estudos de alguns economistas do século XIX, dentre eles, Marshall (1982), que, em seus trabalhos pioneiros sobre o tema, apontou ganhos de eficiência associados ao agrupamento setorial e regional de empresas, as denominadas externalidades positivas.

Outros aspectos relevantes nas aglomerações produtivas foram tratados posteriormente, originando algumas abordagens teóricas (LÜBECK; WITTMAN; SILVA, 2012). Uma delas, 
Setor de gemas e joias da região metropolitana de Belo Horizonte: Um estudo preliminar sob a perspectiva da aglomeração de empresas

encabeçada pelas pesquisas de Krugman (1991, 1999), reúne modelos da nova teoria de crescimento e comércio internacional, nas quais aglomerações produtivas são resultado de economias externas, entendidas como incidentais, e com pouca abertura para as políticas públicas.

Porter $(1993,1998,2000)$ tratou as concentrações geográficas como conexões entre diversos atores, tais como empresas, fornecedores especializados, empresas de indústrias relacionadas, instituições de ensino, centros de pesquisa, entidades governamentais, com intuito de cooperar e alavancar a competitividade. Para esse autor, a presença de um conjunto de fatores locais específicos e determinado volume de empresas de mesma natureza resultam na forma das aglomerações.

Já a abordagem voltada para a economia da inovação em aglomerações apresenta teorias que apontam para diversas políticas de inovação e questões de mensuração; questões relacionadas ao funcionamento interno das empresas e os tipos de práticas de negócios usadas para promover a inovação; a natureza do conhecimento; além de dispor sobre o desenvolvimento dos processos de inovação no âmbito da indústria e nas esferas regionais ou nacionais (Organização para cooperação econômica e desenvolvimento [OCDE], 2004). Trabalhos nesse âmbito foram conduzidos por Nelson e Winter (1992), Freeman (1987), Lundvall (1995), Cooke e Morgan (1998), e Cassiolato e Lastres (1999).

Estudos envolvendo a economia regional, na qual se destacou a importância da cooperação entre pequenas e médias empresas, foram conduzidos por Best (1990), Brusco (1990), Markusen (1995) e mostraram a interdependência entre agentes das aglomerações, fato que levou à necessidade de estruturas de coordenação e políticas públicas de apoio para geração de vantagens competitivas nessas localidades.

Schmitz (1995, 1997, 1999) abordou a eficiência coletiva que pode ser gerada pela aglomeração de empresas. $\mathrm{O}$ autor entende que somente as externalidades positivas decorrentes da proximidade geográfica não é capaz de explicar os benefícios às empresas integrantes das aglomerações, sendo necessária, para se obter a eficiência coletiva, a cooperação - ação conjunta entre agentes privados e setor público.

A definição de sistemas produtivos locais ou arranjos produtivos locais não tem sido uma tarefa fácil para os pesquisadores, uma vez que podem ter variadas caracterizações de acordo com sua história, evolução, organização institucional, sistema de governança, contexto social e cultural (SANTOS; CROCCO; LEMOS, 2002; SUZIGAN et al. 2003a).

Markusen (1995) identificou quatro tipos de distritos industriais: Marshalliano, Centro-Radial (Hub and Spoke), Plataforma Industrial Satélite, e Suportado pelo Estado. O primeiro é composto por pequenas empresas com origem, propriedade, decisões sobre investimentos e produção de base local. As transações favorecem contratos e compromissos de longo prazo, e os encadeamentos ou cooperação com empresas de fora do distrito são quase inexistentes (SANTOS; CROCCO; LEMOS, 2002). O segundo tipo, de acordo com Makusen (1995), o tipo Centro-Radial, é composto por uma estrutura regional que se articula em torno de uma ou várias grandes corporações. Já o distrito do tipo Plataforma Industrial Satélite abriga empresas, subdivisões de multinacionais, que são atraídas pelos incentivos governamentais, baixos salários e impostos. Por último, o distrito suportado pelo Estado consiste na aglomeração em função da existência de instituições de pesquisa ou empresa 
estatal que funcionam como âncora do desenvolvimento econômico regional.

Santos, Crocco e Lemos (2002) propõem uma articulação entre os tipos de distritos industriais propostos por Markusen (1995) e a classificação de aglomerações locais proposto por Mytelka e Farinelli (2000). Segundo estes autores, as aglomerações podem ser classificadas em organizadas, inovativas e informais.

As aglomerações organizadas são sistemas produtivos locais compostos geralmente por pequenas e médias empresas, nas quais a capacidade tecnológica, se não está absolutamente atualizada com a fronteira do conhecimento e do desenvolvimento tecnológico, encontra-se em expansão e, muitas vezes, muito próxima do ideal em termos de equipamentos e processos (SANTOS; CROCCO; LEMOS, 2002).

Aglomerações inovativas são aquelas em que a capacidade inovativa é a grande chave de seu desempenho, assemelhando-se, assim, com a conceituação evolucionista de sistema local de inovação. Apresentam elevada capacidade gerencial e adaptativa, nível e treinamento da mão de obra consideravelmente acima da média, vinculação estreita com o mercado externo, além de um elevado grau de confiança e cooperação entre os agentes (SANTOS; CROCCO; LEMOS, 2002).

No sentido oposto a essas aglomerações, existem as chamadas aglomerações produtivas informais ou de subsistência, que, segundo Santos, Crocco e Lemos, (2002) podem ser classificadas como distritos marshallianos. São geralmente pequenas e médias empresas cujo nível tecnológico é baixo em relação à fronteira da indústria, a capacidade de gestão é precária, a mão de obra existente é pouco qualificada, as formas de coordenação e cooperação são incipientes. A simples concentração de empresas do mesmo setor em determinado território seria capaz de gerar algum efeito positivo, mas insuficiente para tornar realmente competitivo o segmento (SANTOS; CROCCO; LEMOS, 2002 ; CASSIOLATO; LASTRES, 2003).

Diversos estudos (SANTOS; CROCCO; LEMOS, 2002; SUZIGAN et al., 2003a; DEMAJOROVIC; SILVA, 2010) têm adotado a definição de sistemas produtivos e inovativos locais proposta pela Rede de Pesquisa em Sistemas Produtivos e Inovativos Locais - Redesist. Segundo essa definição, sistemas locais de produção e inovação referem-se a "aglomerados de agentes econômicos, políticos e sociais, localizados em um mesmo território, que apresentam vínculos consistentes de articulação, interação, cooperação e aprendizagem" (CASSIOLATO; LASTRES, 2003, p. 5).

As diferentes nomenclaturas de aglomeração não possuem terminologia uniforme entre os autores citados, pois os termos Cluster, Arranjos Produtivos Locais - APLs, Sistemas Locais de Produção e Inovação - SLPI, e Distritos Industriais são tratados, muitas vezes, como similares. Lübeck, Wittman e Silva (2012) propõem variáveis que podem ser adotadas para qualificar os tipos de aglomerações. São elas: capital social; rede de empresas; inovação; políticas públicas; quociente de localização e gini locacional; e indicadores econômicos, que serão apresentadas a seguir.

\subsection{Variáveis para qualificação de a- glomerados empresariais}

A primeira variável discutida por Lübeck, Wittman e Silva (2012) para qualificar e caracterizar concentrações de empresas em determinadas localidades é o capital social.

O capital social é um conceito baseado nos valores associados de pertencer a uma rede social, mas sobre o 
Setor de gemas e joias da região metropolitana de Belo Horizonte: Um estudo preliminar sob a perspectiva da aglomeração de empresas

qual há pouca concordância na literatura. Em geral, é referido como recursos sociais (LIN, 2001), acessados através das conexões que alguém possui em relação a um determinado grupo. Bourdieu (1998), um dos principais teóricos do assunto, define capital social como "recursos reais ou potenciais que estão ligados à posse de uma rede durável de relações mais ou menos institucionalizadas de i n t e r c o n h e c i m e $\mathrm{ntos}$ mútuos" (BOURDIEU, 1998, p. 67).

O capital social está relacionado ao fato de que existem vantagens em pertencer a determinados grupos sociais, vantagens essas que podem ser apropriadas pelo grupo e/ou pelos atores. Os atores, nos grupos sociais, possuem motivações que os levam a determinadas ações, com vistas a investimentos que darão retornos esperados (RECUERO; ZAGO, 2012).

A noção de capital social em APLs e SLPIs passou a ser adotada recentemente, haja vista sua importância para a competitividade e desenvolvimento regional e local, obtido por meio do engajamento (WEGNER; MAEHLER, 2012). O efeito prático é a atuação das instituições locais na promoção de maior inserção social e cooperação, possibilitando atender às demandas da coletividade (LÜBECK; WITTMAN; SILVA, 2012). Ainda de acordo com Lübeck, Wittman; Silva (2012), a cooperação decorrente do capital social facilita a formação de estruturas que coordenem esforços conjuntos em aglomerações. Ressalta-se que, isoladamente, o capital social não é suficiente para caracterizar um APL ou um SPLI.

Outra variável utilizada por Lübeck, Wittman e Silva (2012) para analisar a configuração de arranjos é a rede de empresas. As redes, consideradas como formas de coordenação das atividades socioeconômicas situadas entre as tradicionais formas de coordenação, caracterizadas pela atuação em mercados ou hierarquias, reformulam os princípios da organização burocrática e da hierarquia inflexível, originando, assim, uma ampla gama de relações (SOUZA; CÂNDIDO, 2012).

Lübeck, Wittman e Silva (2012) afirmam que as redes interorganizacionais representam, a partir do capital social, a estrutura formal que sistematiza e coordena relações entre indivíduos e instituições, com o objetivo de gerar desenvolvimento e atendimento aos objetivos locais e regionais.

Dentre as formas de redes, destacam-se os APLs ou SPLIs que, em virtude da importância pela possibilidade de geração de novos empregos, crescimento econômico, aumento de exportações e desenvolvimento tecnológico, vêm recebendo atenção de vários órgãos públicos e instituições privadas como alternativa para $o$ desenvolvimento local.

A rede é pautada em relacionamentos entre atores que são detentores de determinados recursos, e a motivação para a interação está alicerçada justamente na busca por algo que não se tem ou que se tem parcialmente (HAKANSSON; SNEHOTA, 2006). Para Hakansson e Snehota (2006), em redes não há necessariamente a relação somente motivada pela maximização de lucro, mas a busca por maior engajamento em determinado grupo e, com isso, o sentimento de inserção social.

A discussão sobre a formação de redes suscitou questionamentos sobre os reais interesses de se fazer parte de uma rede e também levantou a questão se é possível estabelecer conexões entre atores que competem entre si (BENGTSON; KOCK, 2000; PADULA; DAGNINO, 2007; DEWIT; MEYER, 2010). Tais perguntas tentam ser respondidas tanto pela corrente que aborda a competição, bem como pelos que defendem a colaboração. 
Nos APLs e SPLIs, a formação de redes interempresariais surge para fortalecer as empresas pelo somatório de capacidades individuais, que resulta em melhoria na condição competitiva do arranjo como um todo. Assim, para que sejam caracterizados como APLs ou SPLIs, é necessário que haja conjugação da existência de relações interempresariais e características conectivas apropriadas (LÜBECK; WITTMAN; SILVA; 2012).

A terceira variável - inovação -, considerada por Lübeck, Wittman e Silva (2012), tem sido utilizada com uma variedade de aplicações e significados ao longo dos anos. Estudos modernos realizados acerca de inovação remetem ao trabalho do economista austríaco Joseph Schumpeter, que se destacou pela teoria da "destruição criativa". Tal teoria sugere que o progresso do sistema capitalista acontece por revolucionar constantemente sua estrutura econômica por meio de inovações, sejam elas a criação de novas firmas, novas tecnologias, novos produtos, novos métodos de produção ou transporte, novos mercados e/ou novas formas de organização industrial (SCHUMPETER, 1961).

Tidd, Bressante e Pavitt (2008) resumem o conceito de inovação como algo novo que agregue valor social ou riqueza. Enfatizam que, em termos econômicos, é preciso que haja geração de lucro a partir de tecnologias novas, novos processos, novas práticas mercadológicas e até mesmo pequenas mudanças, ou seja, a denominada inovação incremental (TIDD; BRESSANTE; PAVITT, 2008). A inovação é conceituada não apenas como os avanços realizados na fronteira do conhecimento global, mas também como a primeira vez em que se usa ou se adapta a tecnologia a novos contextos (BANCO MUNDIAL, 2008).

Segundo Castro e Baldi (2010), uma das considerações recorrentes nos trabalhos sobre inovação é a de que raramente as firmas inovam de maneira isolada. A interação com os consumidores, fornecedores, competidores e várias outras organizações públicas e privadas são importantes, e uma perspectiva sistêmica é usada na compreensão e análise dessas interações para que novas combinações (SCHUMPETER, 1961) ou inovações ocorram.

A visão sistêmica desse processo se caracteriza como algo que transcende a esfera da firma individual e passa a depender da contínua interação e cooperação entre empresas e destas com as diferentes instituições. As múltiplas interações internas e externas que podem ocorrer entre os agentes em um determinado ambiente local acabam por influenciar no desempenho inovativo das empresas articuladas em torno de arranjos produtivos locais (SOUZA et al., 2008).

Nesse sentido, os APLs e SPLIs são capazes de afetar a competitividade das organizações, uma vez que aumentam a produtividade, ditam a direção e o ritmo da inovação, além de estimular a criação de novos negócios (PORTER, 1998). A cooperação interempresas propicia a combinação de competências, a utilização de conhecimento de outras empresas, a divisão de custos de pesquisas tecnológicas e o compartilhamento de riscos ao se realizarem experiências em conjunto para explorarem novas oportunidades (AMATO, 2000).

A análise da variável "políticas públicas" também é considerada por Lübeck, Wittman e Silva (2012). Cândido (2002) menciona que as novas formas de desenvolvimento empresarial na economia internacional fazem referência à importância do papel do Estado, sobretudo no que se refere ao esforço em tornar os territórios atrativos.

Segundo Lübeck, Wittman e Silva (2012), as propostas de 
Setor de gemas e joias da região metropolitana de Belo Horizonte: Um estudo preliminar sob a perspectiva da aglomeração de empresas

desenvolvimento local e regional que c ontemplam polític as desenvolvimentistas baseadas em estratégias adaptativas esbarram nas diferenças entre localidades, uma vez que as iniciativas que deram certo em determinado local não necessariamente trarão os mesmos resultados em outro contexto. Um dos caminhos possíveis para adoção de melhores políticas públicas que auxiliem o processo desenvolvimentista é pautar-se na criação e no fortalecimento de organizações e programas que construam ou estruturem modelos de gestão capazes de adotar a aprendizagem como uma das formas de sustentação do desenvolvimento. Ademais, salientam os autores, é preciso implementar estratégias de avaliação capazes de apresentar relações de causa e efeito entre objetivos propostos e resultados obtidos (LÜBECK; WITTMAN; SILVA, 2012).

Muitos estudos têm utilizado a concentração de empresas para identificar APLs, no entanto somente o indicador de quantidade de empresas é insuficiente para tal (LÜBECK; WITTMAN; SILVA, 2012). Em função disso, Lübeck, Wittman e Silva (2012) apresentam a quinta variável, Quociente Locacional (QL) e GINI Locacional (GL), que são medidas para avaliar o grau de especialização e concentração de atividades em determinada região. O cálculo do QL tem sido utilizado por diversos autores para identificar movimentos e tendências de deslocamento regional, assim como para identificação e análise de aglomerações de empresas (SUZIGAN et al., 2003b). Percebe-se que a utilização do QL como forma de identificar um APL é a mais corriqueira, bem como pode demonstrar uma diferenciação produtiva, ou seja, o contrário do esperado do indicador, que é a demonstração da especialização produtiva.

Por fim, Lübeck, Wittman e Silva (2012) apontam que os indicadores econômicos - sexta variável de seu modelo - podem ser adotados para medir a eficiência de um APL ou SPLIs. O impacto provocado no Produto interno bruto (PIB) local e/ou regional deve vir acrescido de outras medidas, tais como análise de mão de obra utilizada, economias de escala, inovação e desenvolvimento tecnológico.

A utilização, pelas organizações, de indicadores disponíveis no mercado para aferição de desempenho é amplamente recomendada, permitindo inclusive comparações externas. (CASSIOLATO; LASTRES, 1999; LÜBECK; WITTMAN; SILVA, 2012).

A partir da literatura estudada e para responder ao problema de pesquisa, foram adotados os procedimentos metodológicos que serão apresentados na próxima sessão.

\section{Procedimentos metodológicos}

De início, é importante ressaltar que o presente artigo faz parte de um projeto mais amplo cujo escopo principal é entender os arranjos produtivos locais do setor de gemas e joias no Brasil. Sendo assim, para alcançar os objetivos traçados para o trabalho, foi realizada uma pesquisa do tipo exploratória, de natureza qualitativa. Levando-se em consideração o contexto estudado, a questão da pesquisa e os objetivos estabelecidos, pode-se afirmar que a metodologia qualitativa se justifica pelo fato de ter um caráter aberto, enfatizando o contexto particular de uma realidade (GODOY, 1995a, 1995b).

Vale destacar que, na visão de Denzin e Lincoln (2006), a pesquisa qualitativa é uma atividade situada que localiza o observador no mundo, consistindo em uma série de práticas materiais e interpretativas, que transformam o mundo em uma série de representações, incluindo as notas de campo, as entrevistas, as gravações e os lembretes. Ou seja, a abordagem 
qualitativa busca uma interpretação detalhada e fidedigna do mundo social no qual se inserem os indivíduos entrevistados (BAUER; GASKELL; ALLUM, 2002). Todos esses aspectos citados parecem ter aderência à proposta de investigar o setor de gemas e joias da Região Metropolitana de Belo Horizonte - RMBH, sob a perspectiva da aglomeração de empresas. A escolha desse setor na RMBH se deu porque estudos anteriores apontaram para a formação de um grande polo joalheiro na região.

Para a obtenção dos dados, optou -se pelo método de entrevista pessoal em profundidade, conforme apresentado por McCracken (1988). Para facilitar a condução das entrevistas e inserir o tema para o entrevistado, foi elaborado um roteiro com questões abertas e amplas. Porém, normalmente, as perguntas foram conduzidas de acordo com as características e os caminhos apontados pelos entrevistados.

Nos estudos qualitativos, é sempre muito discutido o número de entrevistados que o estudo deve conter. Nesse ponto, alguns autores como McCracken (1988) e Morse (1998) sugerem um número entre quatro e oito. Devido à característica exploratória e inicial deste estudo, optou-se por entrevistar sete atores que participam direta ou indiretamente do segmento de gemas e joias da RMBH: um designer; um gerente de produção de uma indústria de joias; um proprietário de uma indústria e comércio de gemas e joias; um proprietário de um comércio de joias; um representante do governo; dois representantes de associação representativa do setor. Os entrevistados foram codificados (E1 a E7) para manter o sigilo de seus nomes.

Desenvolveu-se uma análise do referencial teórico, visando à obtenção de categorias de análise úteis ao estudo e que viabilizassem o alcance do objetivo proposto. Considerando-se que a simples aglomeração de empresas não representa a existência de um APL, aderiu-se ao modelo composto por variáveis necessárias para caracterização de aglomerações, proposto por Lübeck, Wittman e Silva (2012). Segundo esses autores, tais variáveis, apresentadas no Quadro 1, precisam ser observadas e avaliadas, para que não sejam adotadas qualificações equivocadas acerca de um cluster, de um APL ou de um SLPI.

\subsection{Apresentação do setor de gemas e joias de Minas Gerais}

Segundo o Instituto Brasileiro de Gemas e Metais Preciosos (Instituto Brasileiro de Gemas e Metais Preciosos [IBGM], 2013a), o potencial de crescimento da indústria de joias é enorme. $\mathrm{O}$ faturamento do setor em 2012 foi de sete e meio bilhões de dólares, apresentando um crescimento, em relação a 2011, de $7,1 \%$, incluindo exportações, além de ter gerado aproximadamente $\quad 400.000$ (quatrocentos mil) empregos diretos. $\mathrm{O}$ Brasil se posicionou como o $19^{\circ}$ país na produção de joias de ouro e como o $11^{\circ}$ em seu consumo, em 2012. Ainda, de acordo com o IBGM (2013a), o Brasil figura entre os países em que, com rápido crescimento no consumo pós-crise, se prevê significativo aumento de mercados dentro da tendência de se utilizarem joias mais leves, com pedras e outros materiais alternativos.

$\mathrm{O}$ setor de gemas e joias de Minas Gerais é destaque no cenário nacional por sua vocação local, bem como pelos resultados apresentados. Atualmente, o estado de Minas Gerais é o primeiro na exportação de pedras em bruto e pedras lapidadas, figurando ainda entre os três primeiros em artefatos de pedras e joalheria em ouro. Não obstante, houve uma diminuição no volume exportado de pedras em bruto e joalheria em ouro, de 2011 para 2012 , de $14 \%$ e $7 \%$, respectivamente (IBMG, 2013b).

Apesar de o IBGM (2013a) 
Setor de gemas e joias da região metropolitana de Belo Horizonte: Um estudo preliminar sob a perspectiva da aglomeração de empresas

Quadro 1 - Variáveis a serem analisadas em aglomerados empresariais.

\begin{tabular}{|c|c|}
\hline VARIÁVEL & COMO AVALIAR \\
\hline Capital social & $\begin{array}{l}\text { Evidenciar a presença de estruturas de cooperação empresarial e para o desenvol- } \\
\text { vimento local/regional. Tais estruturas são representadas normalmente pelas asso- } \\
\text { ciações empresariais que objetivem o desenvolvimento coletivo. }\end{array}$ \\
\hline Redes de empresas & $\begin{array}{l}\text { Demonstrar a existência e a eficiência e eficácia de atividades cooperadas entre } \\
\text { empresas. }\end{array}$ \\
\hline Inovação & $\begin{array}{l}\text { Identificar níveis de produção de inovações superiores à média obtida no país } \\
\text { (pintec). }\end{array}$ \\
\hline Políticas públicas & $\begin{array}{l}\text { Identificar o incentivo governamental ao desenvolvimento da região, mediante } \\
\text { aportes de recursos destinados para o aglomerado. }\end{array}$ \\
\hline $\begin{array}{l}\text { Quociente de localiza- } \\
\text { ção (QI) e gini locacio- } \\
\text { nal (GI) }\end{array}$ & Aplicar a metodologia quociente de localização (ql) e gini locacional (gl). \\
\hline $\begin{array}{l}\text { Indicadores econômi- } \\
\qquad \cos \end{array}$ & $\begin{array}{l}\text { Os indicadores econômicos locais (IDH, crescimento econômico, desemprego, } \\
\text { escolaridade, etc.) demonstraram níveis de crescimento superiores à média nacio- } \\
\text { nal. }\end{array}$ \\
\hline
\end{tabular}

Fonte: Adaptado de Lübeck, Wittman e Silva, 2012, p. 142.

Para fins deste estudo, tendo em vista seu caráter preliminar e exploratório, optou-se por adotar as variáveis: Capital Social, Rede de Empresas, Inovação, Políticas públicas, que permitem uma abordagem qualitativa, de acordo com Lübeck, Wittman e Silva (2012). As categorias escolhidas foram adotadas como foco principal do estudo, pois resumem o que, na literatura consultada, seriam fatores que ajudam a explicar a identificação de um APL. Tais categorias foram transformadas em um roteiro de entrevista, que foi sendo adaptado à medida que as entrevistas eram realizadas, o que permitiu inserir o aprendizado sobre o tema e ajustar a forma de abordar os atores.

$\mathrm{Na}$ fase de análise dos dados, julgou-se pertinente a utilização da análise de conteúdo. A análise de conteúdo foi elaborada seguindo-se as recomendações de Bardin (1977), que sugere, como primeira etapa, a categorização dos depoimentos, conforme variáveis definidas pelo modelo de Lübeck, Wittman e Silva (2012), e a pré-análise baseada nas transcrições dos depoimentos dos entrevistados. Em um segundo momento, realizou-se a análise profunda das entrevistas. Nessa etapa, houve a transformação dos dados brutos em unidades que permitiram a descrição das características do conteúdo. Por fim, os dados foram tratados e interpretados à luz dos relatos dos entrevistados e das variáveis propostas por Lübeck, Wittman e Silva (2012), e foram comparados ao do referencial teórico, conduzindo às interpretações deste estudo, conforme orienta Bardin (1977). Como forma de complementar as análises e oferecer mais robustez ao estudo, incluiu-se o cálculo do Quociente Locacional (QL). Para tanto, utilizou-se a Relação Anual de Informações Sociais - RAIS (2013), fonte de dados disponível no Brasil e 
disponibilizada pelo Ministério do Trabalho e Emprego para cálculo do referido quociente (QL). Para os propósitos deste trabalho, a base forneceu informações sobre volume de emprego e o número de estabelecimentos do estado de Minas Gerais, desagregados, em termos territoriais, por município e, em termos setoriais, até o nível de quatro dígitos da Classificação Nacional da Atividade Econômica CNAE. Foi adotado o índice de especialização ou QL especificamente aplicado às atividades de Extração de Gemas CNAE 0893-2 e de Lapidação de Gemas e Fabricação de Artefatos de Ourivesaria e Joalheria - CNAE 3211-6, calculado com base nos critérios definidos por Haddad (1999), para os municípios levantados, em 2008, pelo grupo de trabalho para arranjos produtivos locais de Minas Gerais, como participantes do APL de Gemas e Joias da RMBH. Os dados são apresentados na Tabela 1.

Tabela 1 Número de Empresas e Empregos na indústria de gemas e joias

\begin{tabular}{|c|c|c|c|c|c|c|}
\hline RMBH & $\begin{array}{c}\text { Empre- } \\
\text { sas To- } \\
\text { tal }\end{array}$ & $\begin{array}{c}\text { Empre- } \\
\text { gos To- } \\
\text { tal }\end{array}$ & $\begin{array}{c}\text { Empre- } \\
\text { sas Ex- } \\
\text { tracão } \\
\text { de Ge- } \\
\text { mas } \\
\text { CNAE } \\
\text { 0893-2 }\end{array}$ & $\begin{array}{c}\text { Empregos } \\
\text { Extracão de } \\
\text { Gemas } \\
\text { CNAE 0893 } \\
-2\end{array}$ & $\begin{array}{c}\text { Empresas Lapidação } \\
\text { de Gemas e Fabrica- } \\
\text { ção de Artefatos de } \\
\text { Ourivesaria e Joalhe- } \\
\text { ria } \\
\text { CNAE 3211-6 }\end{array}$ & $\begin{array}{l}\text { Empregos Lapi- } \\
\text { dação de Gemas e } \\
\text { Fabricação de } \\
\text { Artefatos de Ouri- } \\
\text { vesaria e Joalheri- } \\
\text { a } \\
\text { CNAE 3211-6 }\end{array}$ \\
\hline Belo Horizonte & 80.453 & $\begin{array}{c}1.377 .68 \\
9\end{array}$ & 67 & 620 & 1 & 5 \\
\hline Betim & 6.160 & 122.688 & 0 & 0 & 0 & 0 \\
\hline Caeté & 645 & 5.281 & 0 & 0 & 0 & 0 \\
\hline Contagem & 13.665 & 212.519 & 1 & 2 & 0 & 0 \\
\hline Ibirité & 1.293 & 16.793 & 0 & 1 & 0 & 0 \\
\hline Lagoa Santa & 1.172 & 14.519 & 1 & 3 & 0 & 0 \\
\hline Nova Lima & 2.332 & 45.486 & 2 & 4 & 0 & 0 \\
\hline Pedro Leopoldo & 1.440 & 16.830 & 0 & 0 & 0 & 0 \\
\hline Raposos & 112 & 832 & 0 & 0 & 0 & 0 \\
\hline $\begin{array}{c}\text { Ribeirão das Ne- } \\
\text { ves }\end{array}$ & 2.407 & 26.704 & 0 & 0 & 0 & 0 \\
\hline Rio Acima & 210 & 1.899 & 0 & 0 & 0 & 0 \\
\hline
\end{tabular}


Setor de gemas e joias da região metropolitana de Belo Horizonte: Um estudo preliminar sob a perspectiva da aglomeração de empresas

\begin{tabular}{|c|c|c|c|c|c|c|} 
Sabará & 1.113 & 17.195 & 0 & 0 & 0 & 0 \\
\hline Santa Luzia & 2.192 & 25.580 & 0 & 0 & 0 & 0 \\
\hline Vespasiano & 1.098 & 18.491 & 1 & 1 & 0 & 0 \\
\hline Total RMBH & $\mathbf{1 1 4 . 2 9 2}$ & $\mathbf{1 . 9 0 2 . 5 0 6}$ & $\mathbf{7 2}$ & $\mathbf{6 3 1}$ & $\mathbf{1}$ & $\mathbf{5}$ \\
\hline & & & & & \\
\hline $\begin{array}{c}\text { Total Minas } \\
\text { Gerais }\end{array}$ & $\mathbf{5 0 1 . 7 8 0}$ & $\mathbf{5 . 0 5 7 . 0 8 0}$ & $\mathbf{1 8 3}$ & $\mathbf{1 . 0 8 7}$ & $\mathbf{4 9}$ & $\mathbf{5 3 0}$ \\
\hline
\end{tabular}

Fonte: BRASIL, 2013.

vislumbrar um crescimento nacional, o setor de gemas e joias em Minas Gerais pode estar ameaçado. A principal explicação é a dificuldade de se conseguir matéria-prima, que agora é disputada com empresários de outros países, principalmente China e Índia. Corre-se o risco de o Estado ficar somente com a exploração dos recursos, sem desenvolvimento da indústria de beneficiamento. $\mathrm{O}$ número de indústrias tem reduzido ano a ano e, consequentemente, a geração de empregos nesse elo da cadeia produtiva (Sindicato das indústrias de joalherias, ourivesarias, lapidações e obras de pedras preciosas, relojoarias, folheados de metais preciosos e bijuterias do estado de Minas Gerais [SINDIJOIAS], 2013).

\section{Análise dos dados e resultados}

O objetivo desta seção é analisar e buscar responder, a partir das respostas dos entrevistados e conceitos atrelados às variáveis Capital Social, Redes de Empresas, Inovação e Políticas Públicas propostas para identificação de um APL (LÜBECK; WITTMAN; SILVA, 2012), se o segmento de gemas e joias da RM$\mathrm{BH}$ pode ser considerado um APL. As evidências são identificadas por sua fonte, citando a codificação usada para repre- sentar os entrevistados, conforme foi explicitado nos procedimentos metodológicos. Também foi realizado, a partir de informações da RAIS e como forma de verificar a especialização produtiva, o cálculo do quociente locacional do setor na RMBH.

\subsection{Capital social}

Observou-se que o segmento de gemas e joias da RMBH, na opinião dos entrevistados, é um "mercado fechado" (E5), no qual "não existe [...] união" (E2), e apesar de se conhecerem, "não têm contato nenhum" (E1). Parece haver uma desconfiança entre os atores da cadeia, que optam por atuarem isoladamente, mesmo reconhecendo que a "falta de acesso a recursos eleva os custos" (E3), e que o capital social poderia facilitar o acesso a esses recursos.

A despeito da constatação da blindagem que ocorre entre os atores do segmento de gemas e joias, iniciativas isoladas de aproximação foram identificadas. O entrevistado E1 declarou que "antigamente um era inimigo do outro. [...] Hoje se reúnem, [...] todo mundo troca ideia, conta o que está acontecendo no mundo. [...] E isso aí, 
vai quebrando um pouco aquela mentalidade que tem que fazer tudo escondidinho". Ainda segundo o E1, foi criada no Sindijoias "uma diretoria de relacionamento entre indústria e varejo", com o objetivo de fomentar as relações e fortalecer os laços. Na avaliação do depoente E3, o setor "começa a ter a ideia de cooperar, mas está muito longe de conseguir organizar direito todos os fatores pra beneficiar a todos", fato que é compartilhado pela afirmativa de que "tem aí uma meia dúzia aí, que faz alguma reunião entre eles aí, mas normalmente os pequenos [...] são excluídos" (E3).

A ideia de compartilhamento de recursos foi mencionada como algo que possibilitaria obter ganhos de produtividade e redução de custo, por meio do uso "técnicas mais avançadas, [...] com profissionais mais bem preparados e maquinário atualizado" (E1). A percepção que se tem, por meio dos relatos, é que muitos profissionais "práticos" ou artesãos estão deixando de atuar e não está ocorrendo a transferência do conhecimento, tampouco iniciativas para renovar e capacitar mão de obra especializada para o setor. Resultado disso é que "a mão de obra [brasileira] é bem mais cara, mas a gente não tem a qualidade que eles [chineses] têm. [...] lapidar ela [uma pedra] não compensa financeiramente $\mathrm{e}$ não tem essa perfeição" (E3). Isso resulta numa crescente entrada de pedras (gemas) lapidadas, oriundas principalmente da China, que desembarcam no País por um preço infinitamente menor e de qualidade superior.

Considerando-se que o capital social tem um importante papel no acesso a recursos, dentre eles, a aquisição e criação de conhecimento por parte das empresas que o possuem (NAHAPIET; GOSHAL, 1998), entende-se que o volume do capital social de cada empresa influencia na obtenção de vantagem competitiva e conduz a melhor desempenho (WEGNER; MAEHLER, 2012). Nesse sentido, a formação de APLs pode sugerir a existência das características autopoiéticas do capital social, promovidas pelo engajamento e pela cooperação (LÜBECK; WITTMAN; SILVA, 2012).

Assim, ao analisar a construção do capital pelos atores pertencentes ao segmento de gemas e joias da RMBH, observa-se que, exceto iniciativas isoladas e de pouco vulto, conduzidas principalmente por um pequeno grupo dos considerados "maiores", não há evidências de cooperação e confiança nas relações sociais desenvolvidas nesse segmento. Essas constatações permitem elaborar a proposição:

Proposição 1: não se reconhecem ações efetivas de desenvolvimento e aproveitamento do capital social do segmento de gemas e joias da RMBH por parte dos empresários do setor.

\subsection{Redes de empresas}

A análise da existência de relações cooperadas entre a rede de empresas constituintes de um APL é para Lübeck, Wittman e Silva (2012) um indicativo do nível de evolução e eficiência do arranjo. No caso do segmento de gemas e joias da RMBH, as ações de cooperação entre as empresas do setor parecem não representar exemplo de relações interempresariais baseadas na confiança, na troca de informações e no compartilhamento de recursos. Segundo exemplo do E1, sua indústria possui cinco desenhistas, o que representa grande custo para a empresa, quando o ideal fosse a existência "de um núcleo de design, [...] prestando serviços para um conjunto". Para este entrevistado, a ideia da formação do arranjo na RMBH previa não só a formação de um centro de design que pudesse atender a diferentes empresas mas também outros serviços que pudessem ser compartilhados, como o processo de fundição, cujo maquinário necessita ser permanentemente atualizado. Para E2 e E3 "o mercado é muito fechado", "a gente não procura invadir o espaço do 
Setor de gemas e joias da região metropolitana de Belo Horizonte: Um estudo preliminar sob a perspectiva da aglomeração de empresas

outro, trocar informação" (E2), "não adianta você ter muita curiosidade em saber, porque você não vai ficar sabendo" (E3). Da mesma forma, para E5, o "segmento é fragmentado", "não há confiança, concorrentes trazem joia da China e não se sabe a procedência". Ou seja, "a concorrência no segmento é muito desleal" (E5).

A visão de cooperação parece se resumir às relações terceirizadas. Segundo E2, neste setor "você tem que correr atrás e fazer o seu", mas "nós temos uma outra turma que a gente faz uma parceria. [...] a gente terceiriza o trabalho quando aperta muito lá pra gente". A análise dos depoimentos permite constatar que as empresas do segmento de gemas e joias da RMBH atuam de maneira isolada, sem praticamente interação entre elas, para exercício de qualquer uma das funções inerentes à gestão organizacional, seja investimento em P\&D, comercialização, produção, ou mesmo compras conjuntas. Nesse sentido, essa aglomeração pode ser classificada como um arranjo informal, de sobrevivência, caracterizado por baixo fluxo de informação e geração de conhecimento interfirmas, com forte predomínio de competição em relação às ações de colaboração (PEREIRA; GUIMARÃES, 2011). A constatação da ausência de redes de empresas nesse segmento permitiu elaborar a seguinte proposição:

Proposição 2: as empresas componentes do segmento de gemas e joias da RMBH não desenvolveram relações colaborativas no sentido de facilitar o fluxo de informações e a geração de conhecimento, o compartilhamento no uso de recursos, o que, portanto, mantém o setor pouco competitivo e enfraquecido para atuação coletiva.

\subsection{Inovação}

Identificou-se que o segmento de gemas e joias da RMBH é um "mercado muito fechado, [...] não se invade o espa- ço do outro, [não há] troca de informação" (E2). Visto que a inovação é fruto de ligações entre empresas, sua existência fica comprometida ou até mesmo inviabilizada por ser um processo complexo se desenvolvido isoladamente (CASTRO; BALDI, 2010).

As novidades no segmento de gemas e joias da RMBH são essencialmente buscadas por meio de feiras que "é bom pra você pegar ideias, é bom pra você fazer contatos" (E3) e "buscar novos modelos de peças" (E2). Mas é notório que "praticamente não há inovação no setor" (E3). Uma das queixas é que "não tem como [...] estar inovando, por causa dos equipamentos, os equipamentos é caro demais" (E3).

Dá-se mais atenção ao produto do que ao processo produtivo. Nas feiras, a procura é por novos modelos de joias que, posteriormente, serão copiados " $[$...] o segmento copia demais, é impressionante" (E2). O processo produtivo é tido por alguns como estagnado, com tendência ao declínio, tendo em vista que, por um lado, "os lapidários aqui [em Belo Horizonte] têm uma equipe muito boa" (E2), e, por outro lado, há uma migração e "muita gente está saindo pra fora do Brasil, está fazendo [produzindo] lá na China" (E3). Identificou-se que "tem inovação de todos os lados, então tem dentro das universidades [...] agora, como que isso sai da universidade e vai pra indústria é outros quinhentos" (E4), corroborando a necessidade da adoção do modelo da tríplice hélice - ou seja, estabelecimento de parceria entre governouniversidade-indústria - para que a inovação aconteça (ETZKOWITZ, 2008).

Segundo um dos entrevistados, o segmento de gemas e joias brasileiro, buscando diferenciação e competitividade, destacou-se no cenário internacional, pela "criatividade, [ao] criar uma joia com a cara do Brasil" (E1). Para tanto, valorizou-se a "pedra/gema brasileira, que ganhou espaço nacional e internacional" (E5). Foi um grande salto propor- 
cionado especialmente pelos concursos de design de joias, que passaram a exigir pedras brasileiras nas criações dos participantes.

O estado de Minas Gerais destaca -se no cenário nacional e internacional por seus designers que despontam na obtenção de prêmios em concursos nacionais e internacionais. Apesar de "[Minas Gerais] ser muito forte no design, só que [...] isso não se reflete em benefícios pra indústria" (E4). O que os depoentes querem dizer é que, a despeito das inúmeras premiações angariadas pelos designers mineiros em concursos promovidas por organizações do segmento, isto ainda não é devidamente capitalizado em termos de diferencial para a indústria mineira e para a joalheria nacional.

Observa-se que há uma desarticulação entre os atores do segmento de gemas e joias da RMBH, cada qual buscando a competitividade e sobrevivência de forma isolada, sem iniciativas de cooperação e interação, gerando resultados inexpressivos no que diz respeito à inovação, podendo considerá-lo incipiente. Assim, apesar dos agentes reconhecerem a relevância da atuação em rede para os processos de inovação, não se tem um movimento coordenado para que essa aproximação se consolide. Nesse sentido, as afirmativas acerca da influência no desempenho inovativo de empresas que estão articuladas em torno de arranjos produtivos locais (SOUZA et al., 2008) parecem não refletir a prática no segmento de gemas e joias da RMBH.

Ao se analisarem as ações de inovação efetuadas pelo segmento de gemas e joias localizado na RMBH, percebe-se que, na verdade, não se pode afirmar que efetivamente ocorram iniciativas que possam ser consideradas inovadoras, tanto em processo quanto em produtos/ design. Percebe-se que há um predomínio de trabalhos de imitação da indústria joalheira internacional e uso de réplicas consagradas pelo mercado. Talvez o in- vestimento de maior relevância na valorização das joias nacionais tenha ocorrido a partir da decisão de uso de gemas coradas - abundantes no Brasil e, especialmente em Minas Gerais - como forma de promover uma identidade brasileira a produto dessa categoria. Essas constatações permitem elaborar a proposição:

Proposição 3: apesar da projeção do Estado de Minas Gerais na indústria joalheira, não há iniciativas e resultados relevantes no que diz respeito à inovação para o setor.

\subsection{Políticas públicas}

Em relação às políticas públicas voltadas para o segmento de gemas e joias, há uma percepção generalizada de que o "governo não incentiva" (E5, E6, E7). As queixas principais são relativas ao alto custo dos tributos e encargos trabalhistas e à falta de fiscalização do setor. $\mathrm{O}$ entrevistado $\mathrm{E} 3$ afirma que terceiriza tudo [...] não tenho incentivo nenhum, não tem por que ter empregado". Há relatos também voltados para a informalidade e o contrabando no setor, principalmente "no varejo e o que mais se encontra é pedra falsa e o mercado informal" (E1). Essa situação, na visão dos depoentes, gera uma "concorrência desleal" (E3, E5) tanto no varejo, por parte das chamadas "sacoleiras", bem como em outros elos da cadeia produtiva, em função do contrabando, especialmente de gemas. Para a questão da informalidade, observa-se que há uma expectativa de formalização dos negócios, que cresça "muito o trabalho dos autônomos com esse negócio de microempreendedor individual" (E4).

No que diz respeito às ações voltadas para a formação e desenvolvimento de APLs, secretários do governo de Minas Gerais, ao detectarem a importância dos APLs na política estadual, aprovaram, em 2006, a lei que institucionalizou a política para APLs e, decorrente dessa política, foi instalado, em 2008, o Nú- 
Setor de gemas e joias da região metropolitana de Belo Horizonte: Um estudo preliminar sob a perspectiva da aglomeração de empresas

cleo Gestor de APLs (NGAPL) (BOTELHO et al., 2010).

Mais especificamente em relação ao segmento de gemas e joias da RMBH, identificou-se que o APL de gemas e joias, cujo polo seria no município de Nova Lima, foi citado em documento fruto do projeto "Análise do Mapeamento e das Políticas para Arranjos Produtivos Locais no Sul, Sudeste e Centro-Oeste do Brasil", realizado pelo Banco Nacional de Desenvolvimento Econômico e Social [BNDES] (2010). No referido documento, o Núcleo Gestor de APLs (NGAPL) identificou o APL, em nível estadual, e considerou-o como um dos prioritários para apoio do governo do estado de Minas Gerais (BNDES, 2010).

Sabe-se que houve forte movimento encabeçado pelo sindicato patronal, em parceria com a iniciativa privada, apoio de instituições setoriais e anuência do governo do estado, para a formação de um APL de gemas e joias na RMBH o chamado APL de gemas e joias de Nova Lima; no entanto, entraves burocráticos colocaram uma pausa no projeto. Ademais, a visão de resultado de curto prazo adotada pelos gestores públicos, citada pelo entrevistado E1, contribuiu para não continuidade desse empreendimento.

Apesar de o estado de Minas Gerais ter instrumentalizado a temática acerca dos APLs e identificado o APL de gemas e joias de Nova Lima, ou APL de gemas e joias da RMBH, isso não foi relatado pelos entrevistados, tampouco os resultados foram visíveis. Atualmente, o chamado APL de gemas e joias de Nova Lima não figura mais entre os APLs prioritários, e não há outros "projetos apoiados pelo governo do Estado nesse segmento" (E7).

Percebe-se que, embora tenha havido avanços nas iniciativas políticas, no que se refere especialmente aos APLs, as ações são, em grande maioria, baseadas em modelos de apoio pontuais e têm em seu núcleo apenas a oferta de produtos tradicionais utilizados pelos atores, sem que haja definição de estratégias voltadas tanto para as necessidades e oportunidades do local, quanto para o desenvolvimento sistêmico (BOTELHO et al., 2010).

Observa-se ainda que o segmento de gemas e joias de Minas Gerais, a despeito de sua representatividade nacional e tradição local, pode ter perdido, sob a perspectiva dos APLs, o status de prioritário para o governo do Estado.

Esse fato parece ter relação com os próprios critérios utilizados para caracterização de um APL, dentre eles, principalmente sua forma e seu grau de desenvolvimento, representada pela capacidade de mobilizar e coordenar a ação coletiva - governança local, ou pela existência e qualidade dos vínculos entre as empresas e demais atores (GARCEZ et al., 2010). Essas constatações permitem elaborar a proposição:

Proposição 4: não obstante a instrumentalização do tema APLs pelo governo do estado de Minas Gerais, não há iniciativas efetivas voltadas para a formação e o desenvolvimento de um APL de gemas e joias na RMBH.

\subsection{Quociente locacional}

Conforme Santos et al. (2006), para que exista especialização de determinado setor de determinada região, o QL deve ser superior a 1. Os resultados dos índices de especialização, calculados a partir dos critérios definidos na metodologia, para os municípios indicados como participantes do APL de Gemas e Joias da RMBH, são apresentados na Tabela 2. 
Tabela 2 Quocientes Locacionais para as classes da indústria de Gemas e Joias da RMBH

\begin{tabular}{|c|c|}
\hline RMBH & QL \\
\hline Belo Horizonte & 1,419 \\
\hline Betim & 0,000 \\
\hline Caeté & 0,000 \\
\hline Contagem & 0,029 \\
\hline Ibirité & 0,186 \\
\hline Lagoa Santa & 0,646 \\
\hline Nova Lima & 0,275 \\
\hline Pedro Leopoldo & 0,000 \\
\hline Raposos & 0,000 \\
\hline Ribeirão das Neves & 0,000 \\
\hline Rio Acima & 0,000 \\
\hline Sabará & 0,000 \\
\hline Santa Luzia & 0,000 \\
\hline Vespasiano & 0,169 \\
\hline Total RMBH & 1,045 \\
\hline
\end{tabular}

Fonte: Elaborado Fonte: Elaborado pelos autores com base nos dados da RAIS/MTE (2013)

Apesar de o QL total ter sido superior a 1 , influenciado fortemente pelo resultado da capital do estado, Belo Horizonte, vale ressaltar que esse índice é adequado para regiões de porte médio, nas quais os resultados obtidos são mais coerentes. A heterogeneidade das indústrias brasileiras faz com que haja diversos setores econômicos nas cidades que podem apresentar um QL acima de 1, mesmo que tais setores não possuam uma especialização produtiva. Crocco et al. (2003) afirmam que o ponto de corte para determinar se uma região possui especialização deveria ser significativamente acima de 1 e que tal indicador é mais apropriado para regiões de porte médio. Em regiões de pequeno porte ou de estrutura produtiva diversificada, esse indicador pode sobrevalorizar ou subvalorizar o setor, respectivamente. A partir do exposto, esboça-se a seguinte proposição:

Proposição 5: embora o QL do setor de gemas e joias na RMBH tenha sido ligeiramente superior a 1 , não se pode afirmar que há concentração dessa in- dústria na região.

\section{Considerações finais}

O presente artigo teve como proposta central analisar o segmento de gemas e joias da RMBH sob a perspectiva da aglomeração de empresas, com o intuito de identificar se este apresenta características necessárias para ser identificado como um APL. Para tal, foi adotado o modelo proposto por Lübeck, Wittman e Silva (2012), do qual foram extraídas e analisadas as variáveis: Capital Social, Rede de empresas, Inovação, Políticas Públicas e cálculo do Quociente Locacional.

Com relação às reflexões acerca da formação de capital social pelos atores do segmento de gemas e joias da $\mathrm{RMBH}$, parece não haver confiança e cooperação entre as partes, o que culmina na inexistência de estruturas que objetivem o desenvolvimento coletivo. Assim, o acesso a determinados recursos que poderiam ser obtidos por meio 
Setor de gemas e joias da região metropolitana de Belo Horizonte: Um estudo preliminar sob a perspectiva da aglomeração de empresas

dessa variável, torna-se inviável, devida à baixa utilização do capital social. No que tange à formação de uma rede de empresas do segmento de gemas e joias da RMBH, constata-se que é um setor muito fechado, no qual as empresas praticamente não se relacionam, a não ser por meio de transações comerciais baseadas em preços. Dessa forma, não há indícios de existência de atividades cooperadas entre as organizações, predominando as ações de competição ou sentimento de indiferença. Quanto à questão da inovação no segmento de gemas e joias da RMBH, observa-se que não há mudanças e aperfeiçoamentos no processo produtivo, tampouco inovação em produto/design. As fábricas do segmento privilegiam acompanhar tendências internacionais e realizar cópias dos lançamentos. Vale ressaltar que o estado de Minas Gerais se destaca no cenário nacional, tanto pela produção de gemas quanto pela presença de designers renomados, no entanto essa "riqueza" parece não garantir que a inovação alcance o segmento como um todo. No que diz respeito à variável "políticas públicas", constata-se que não há iniciativas governamentais voltadas para projetos envolvendo aporte de recursos destinado ao segmento de gemas e joias da RMBH. Por fim, quanto à variável "quociente locacional", apesar de o resultado ser superior a 1 , o que caracterizaria uma região de indústrias especializadas, vale a ressalva de Crocco et al. (2003), que, para grandes cidades, com setores econômicos heterogêneos, o índice deveria ser significativamente superior a 1 para indicar um padrão de especialização produtiva.

Portanto, identificou-se que o segmento de gemas e joias da RMBH não apresenta algumas daquelas condições apontadas por Lübeck, Wittman e Silva (2012) como necessárias para a formação de um APL: existência de capital social, formação de redes de empresas, níveis de inovação superiores, políticas públicas de apoio $\mathrm{e}$ quociente locacional significativamente superior a um. A aglomeração analisada apresenta baixo capital social e inovação incipiente, rede de empresas pouco significativa e ausência de políticas públicas destinadas ao setor. Cabe ressaltar, podendo ser considerada uma limitação do estudo, que a variável "indicadores econômicos" não foi avaliada, o que restringe afirmativas contundentes acerca da classificação proposta pelos autores.

É importante salientar que, sendo estudo exploratório, há outros pontos limitadores. Um deles remete à questão do tamanho da amostra. Ainda que alguns autores, conforme apresentado na seção da metodologia, estabeleçam que, em um estudo de cunho exploratório com técnicas qualitativas, o número de sete entrevistados é suficiente, um número maior de entrevistas poderia prover robustez ao trabalho. Atrelado a esse aspecto, levanta-se a não possibilidade de generalização dos resultados do estudo. O segundo ponto a destacar é a característica dos entrevistados. A grande maioria, com exceção do presidente do sindicato do setor, atua em empreendimentos de pequeno porte, o que pode ter enviesado as respostas.

A partir daí, sugestões para estudos futuros podem ser apontadas. Em se tratando do segmento de joias da RMBH, as proposições elaboradas poderiam ser testadas a partir de uma amostra mais significativa de empresas que atuam na cadeia produtiva. Complementarmente, seria interessante analisar isoladamente cada elo da cadeia para compreender suas características e comportamentos específicos e, em seguida, compará-los com os demais. Além disso, seria essencial estudos incluindo as empresas de grande porte, que podem apresentar uma visão diferente acerca do tema e das variáveis analisadas. Do ponto de vista de implicações práticas, vale ressaltar que os resultados deste artigo apontam para a necessidade de políticas públicas que promovam ações que fortaleçam o segmento, bem como projetos de associações de classe, de forma a tornar mais competitiva a aglomeração de joias da RMBH, o que, consequentemente, ajudaria a alavancar o desenvolvimento econômico e social do Estado de Minas Gerais. 


\section{Referências}

AMATO, J. N. Redes de cooperação produtiva e clusters regionais: oportunidades para as pequenas e médias empresas. São Paulo: Atlas, 2000.

BANCO MUNDIAL. Conhecimento e inovação para a competitividade. Trad. Confederação Nacional da Indústria. Brasília: CNI. Disponível em: <http:// www.worldbank.org/pt/country/brazil>. Acesso em: 20 de jan. 2014.

BANCO NACIONAL DE DESENVOLVIMENTO ECONÔMICO E SOCIAL. Caracterização, análise e sugestões para adensamento das políticas de apoio a APLs implementadas: o caso do Estado de Minas Gerais. Disponível em: <http:// www.bndes.gov.br>. Acesso em: 20 de jan. 2014.

BARDIN, L. Análise de conteúdo. Lisboa: Edições 70, 1977.

BAUER, M. W.; GASKELL, G.; ALLUM, N. C. Qualidade, quantidade e interesses de conhecimento: Evitando confusões. In: BAUER, M. W., GASKELL, G. (Org.) Pesquisa qualitativa com texto, imagem e som: um manual prático. São Paulo: Vozes, 2002.

BENGTSSON M.; KOCK S. Coopetition in business networks: to cooperate and compete simultaneously. Industrial Marketing Management, v. 29, n. 5, p. 411-26, 2000.

BEST, M. The new competition: institutions of industrial restructuring. Cambridge: Harvard University Press, 1990.

BOTELHO, M. R. A. et al. Políticas para arranjos produtivos locais no Estado de Minas Gerais: institucionalidade, mapeamentos e focos. In: Campos, R. R., et al. (Orgs.) Políticas estaduais para arranjos produtivos locais no Sul, Sudeste e CentroOeste do Brasil. Rio de Janeiro: E-papers,
2010.

BOURDIEU, P. O capital social: notas provisórias. In: CATANI, A.; NOGUEIRA, M. A. (Orgs.). Escritos de Educação. Petrópolis: Vozes, 1998.

BRASIL. Ministério do Trabalho e Emprego - MTE. Relação Anual de Informações Sociais - RAIS. 2013.

BRUSCO S. The rules of the game in industrial districts. In: GRANDORI A. Interfirm networks: organization and industrial competitiveness. London: Routledge, 1999.

CÂNDIDO, G. A. A formação de redes interorganizacionais como mecanismos para geração de vantagem competitiva e para promoção do desenvolvimento regional: o papel do estado e das políticas públicas neste cenário. Revista de Administração, v. 28 n. 4, p. 1-17, 2002.

CASSIOLATO, J. E.; LASTRES, H. M. M. Inovação, globalização e as novas políticas de desenvolvimento industrial e tecnológico. In: CASSIOLATO, J. E.; LASTRES, H. M. M. (Orgs). Globalização e inovação localizada: experiências de sistemas locais no Mercosul. Brasília: IBICT/MCT,1999.

CASSiOLATO, J. E.; LASTRES, H. M. M. $O$ foco em arranjos produtivos e inovativos locais de micro e pequenas empresas: cooperação e desenvolvimento local. Brasília, DF: Relume Dumará, 2003.

CASTRO, R. B.; BALDI, M. A inovação no polo joalheiro de Belém: uma análise a partir do mecanismo de imersão estrutural. Cadernos EBAPE.BR, Rio de Janeiro, v. 8, n. 3, 2010.

COOKE, P.; MORGAN, K. The associational economy: firms, regions, and innovation. Nova York: Oxford University Press, 1988.

CROCCO et al. Metodologia de identificação de arranjos produtivos locais poten- 
Setor de gemas e joias da região metropolitana de Belo Horizonte: Um estudo preliminar sob a perspectiva da aglomeração de empresas

ciais: uma nota técnica. Belo Horizonte: UFMG, 2003.

DEMAJOROVIC, J.; SILVA, A.V. Arranjos produtivos locais e práticas de gestão socioambiental: Uma análise do polo moveleiro de Arapongas. Revista Ambiente \& Sociedade, v. 13, n. 1, p. 131-49, jan./jun. 2010 .

DENZIN, N. K.; LINCOLN, Y. S. O planejamento da pesquisa qualitativa: teorias e abordagens. 2. ed. Porto Alegre: Bookman, 2006.

DEWIT B.; MEYER, R. Strategy: process, content, context: an international perspective. Zrinski: CENGAGE Learning, 2010.

ETZKOWITZ, H. The triple helix: university-industry-government innovation in action. New York and London: Routledge, 2008.

FREEMAN, C. Technology and economic performance: lessons from Japan. London: Pinter Publishers, 1987.

GARCEZ, C. et al. Análise de políticas para arranjos produtivos locais no Brasil: uma introdução. In: Campos, R. R.; et al (Orgs.). Políticas estaduais para arranjos produtivos locais no Sul, Sudeste e Centro-Oeste do Brasil. Rio de Janeiro: E-papers, p. 3539. 2010.

GODOY, A.S. Pesquisa qualitativa e sua utilização em administração. RAE-Revista de Administração de Empresas, São Paulo: FGV, v. 1, n. 3, p. 85-94, 1995a.

GODOY, A.S. Introdução à pesquisa qualitativa e suas possibilidades. RAE-Revista de Administração de Empresas, São Paulo: FGV, v. 2, n. 35, p. 57-63, 1995 b.

HADDAD, P. R. Medidas de localização e de especialização. In: HADDAD, P. R. et al. (Org.). Economia regional: teorias e métodos de análise. Fortaleza: BNB-
ETENE, 1989.

HAKANSSON, H.; SNEHOTA, I. No business is an island: the network concept of business strategy. Scandinavian Journal of Management, v. 22, n. 3, p. 256-70, 2006.

HENRIQUES, H. S.; SOARES, M. M. (Coords.). Políticas e ações para a cadeia produtiva de gemas e joias. Brasília: Brisa, 2005. Disponível em: <http:// www.sistemamodabrasil.com.br/ $\begin{array}{llllllllll}\mathrm{d} & \mathrm{o} & \mathrm{c} & \mathrm{u} & \mathrm{m} & \mathrm{e} & \mathrm{n} & \mathrm{t} & \mathrm{s} & /\end{array}$ panorma_setorial_gemas_joias.pdf >.Acesso em: 14 de jan. 2014.

INSTITUTO BRASILEIRO DE GEMAS E METAIS PRECIOSOS. O setor de gemas e joias no Brasil, 2010. Disponível em < http://brazilgemsandjewelry.com $>$. Acesso em: 01 set. 2013.

INSTITUTO BRASILEIRO DE GEMAS E METAIS PRECIOSOS. Informações do Setor, 2013a. Disponível em <http:// ibgm.com.br>. Acesso em: 01 set. 2013.

INSTITUTO BRASILEIRO DE GEMAS E METAIS PRECIOSOS. Exportação brasileira de gemas, joias e bijuterias, 2013b. Disponível em <http://ibgm.com.br>. Acesso em: 01 set. 2013.

KRUGMAN, P. Geography and trade. Cambridge, MA: MIT Press, 1991.

KRUGMAN, P. The role of geography in development. In: PLESKOVIC, B.; STIGLITZ, J. E. Annual world bank conference on development economics, 1998. Washington, DC: The Word Bank. 1999.

LIN, N. Social capital: A theory of social structure and action. Cambridge: Cambridge University Press, 2001.

LÜBECK, R. M.; WITTMANN, M. L.; SILVA, M. S. da. Afinal, quais variáveis caracterizam a existência de cluster arranjos 
produtivos locais (APLs) e dos sistemas locais de produção e inovação (SPLIs)? Revista Ibero-Americana de Estratégia RIAE, São Paulo, v.1, n.11, p. 120-151, 2012.

LUNDVALL, B. A. National systems of innovation: towards a theory of innovation and interactive learning. Londres: Pinter, 1995.

MARKUSEN, A. Áreas de atração de investimentos em um espaço econômico cambiante: uma tipologia de distritos industriais. Revista Nova Economia, Belo Horizonte, v. 2, n. 5, p. 9-44, 1995.

MARSHALL, A. Princípios de economia: tratado introdutório. São Paulo: Abril Cultural, 1982. V. 2, p. 231-239.

McCRACKEN, G. The long interview. London: Sage Publications, 1988.

MORSE, J. M. Designing Funded Qualitative Research. In: DENZIN, N. K.; LINCOLN, Y. Strategies of Qualitative Inquiry. London: Sage Publications, 1998.

MYTELKA, L.; FARINELLI, F. Local clusters, innovation systems and sustained competitiveness. In: SEMINÁRIO LOCAL CLUSTERS, INNOVATION SYSTEMS AND SUSTAINED COMPETITIVENESS, IE-BNDES, Nota técnica 5, Rio de Janeiro, 2000 .

NAHAPIET, J.; GOSHAL, S. Social capital, intellectual capital, and the organizational advantage. Academy of Management Review, v. 23, n. 2, p. 242-266, 1998.

NELSON, R. R.; WINTER, S. G. An evolutionary theory of economic change. Cambridge: The Belknap Press of Harvard University Press, 1992.

PADULA, G.; DAGNINO, G. Untagling the rise of competition: the intrusion of competition in a cooperative game structure. Inter- national Studies of Management \& Organization, v. 37, n. 2, p. 32-53, 2007.

PORTER, M. E. Vantagem competitiva das nações. Rio de Janeiro: Campus, 1993. PORTER, M. E. Clusters and the new economics of competition. Harvard Business Review, v. 76, n. 6, p. 77-90, Nov./Dec. 1998.

PORTER, M. E. Location, competition, and economic development: local clusters in a Global Economic Development Quarterly. v. 14, n. 1, p. 15-34, Feb. 2000.

RECUERO, R.; ZAGO. A Economia do Retweet: Redes, Difusão de Informações e Capital Social no Twitter. Revista Contracampo, v. 1, n. 24, p. 19-43. 2012.

SANTOS, F.; CROCCO, M.; LEMOS, M.

B. Arranjos e sistemas produtivos locais em "espaços industriais" periféricos: estudo comparativo de dois casos brasileiros. Belo Horizonte: UFMG/Cedeplar, 2002. 27p.

Texto para discussão n. 182. 2002.

SANTOS, S. B. S. et al. Proposta de metodologia de identificação de clusters: uma aplicação ao turismo. In: Colóquio Internacional sobre Poder Local, 2006, Salvador... Anais: Salvador, Brasil, 10. 2006.

SCHMITZ, H. Small shoemakers and fordist giants: tale of a supercluster. World Development, v. 23, n.1, p. 9-28, 1995.

SCHMITZ, H. Colletive efficiency and increasing retuns. IDS Working Paper Brighton: Institute For Development Studies, University of Sussex. 1997.

SCHMITZ, H. Global competition and local cooperation: success and failure in the Sinos Valley.World Development, v. 27, n. 9, p. 1627-1650, 1999.

SCHUMPETER, J. A. Capitalismo, socialismo e democracia. Rio de Janeiro: Edito- 
Setor de gemas e joias da região metropolitana de Belo Horizonte: Um estudo preliminar sob a perspectiva da aglomeração de empresas

ra Fundo de Cultura, 1961.

SINDICATO DAS INDÚSTRIAS DE JOALHERIAS, OURIVERSARIAS, LAPIDAÇÕES E OBRAS DE PEDRAS PRECIOSAS, RELOJOARIAS, FOLHEADOS DE METAIS PRECIOSOS E BIJUTERIAS DO ESTADO DE MINAS GERAIS, 2013. Disponível em http://sindijoiasmg.com.br/ plus/>. Acesso em: 7 set. 2013.

SOUZA, M. P. et. al. Dimensão da Inovação em Arranjos Produtivos Locais. In: ENCONTRO ANPAD. 32, 2008, Rio de Janeiro. Anais... Rio de Janeiro: ANPAD, 2008, p. 1-16.

SOUZA, S. M. A. de.; CÂNDIDO, G. A. Proposta de critérios para análise de estruturas de governança em redes interorganizacionais: o caso dos arranjos produtivos locais. In: Encontro de Estudo Organizacionais da Anpad. 7, 2012, Curitiba. Anais... Curitiba: ANPAD. p. 1-16, 2012.

SUZIGAN, W.; FURTADO, J.; GARCIA, R.; SAMPAIO, S. Sistemas locais de produção: mapeamento, tipologia e sugestões de políticas. In: ENCONTRO NACIONAL DE ECONOMIA DA ANPEC, 31. Anais... Porto Seguro. 2003a.

SUZIGAN, W.; FURTADO, J.; GARCIA, R.; SAMPAIO, S. Coeficientes de Gini locacionais - GL: aplicação à indústria de calçados do Estado de São Paulo. Nova Economia, V. 13, n. 2, p. 39-60. 2003 b.

TIDD, J.; BESSANT, J.; PAVITT, K. Gestão da Inovação. 3. ed. Porto Alegre: Bookman, 2008.

WEGNER; D.; MAEHLER; A. E. Desempenho de empresas participantes de rede interorganizacionais: analisando a influência do capital social e da capacidade absortiva. Revista Gestão e Planejamento, Salvador, v. 2, n.13, p. 191-211, maio/ago. 2012. 